ACTA SCIENTIFIC NUTRITIONAL HEALTH (ISSN: 2582-1423)

Volume 3 Issue 8 August 2019

Short Communication

\title{
Low Body Mass Index and High Body Fat Percent in Asian Populations
}

\section{Saijuddin Shaikh*}

Associate, Department of Nutrition and International Health, Johns Hopkins University, Baltimore, USA

*Corresponding Author: Saijuddin Shaikh, Associate, Department of Nutrition and International Health, Johns Hopkins University, Baltimore, USA.

Received: July 16, 2019; Published: July 31, 2019

DOI: 10.31080/ASNH.2019.03.0392

Overweight and obesity are recognized as a global health problem and rapidly escalating in developing countries. Excess body fat is associated with several non-communicable diseases and increase risk of mortality [1], type 2 diabetes [2], cardiovascular diseases and cancer [3]. Obese individuals have 7 times higher risk of developing diabetes than individuals [4] of normal body mass index (BMI). It has been estimated that nearly one-third of the world population are overweight or obese by 2030 [5]. Accurate determination of obesity is very important because of major health threats posed by excess adiposity. However, BMI, calculating by weight $(\mathrm{kg}) /$ height $\left(\mathrm{m}^{2}\right)$, an important indicator of obesity measurement in large population, since BMI over- or underestimate adiposity depending upon certain circumstances.

It is reported by WHO expert committee [6] that in an identical BMI $\left(22.3 \mathrm{~kg} / \mathrm{m}^{2}\right)$, body fat percent measured by dual X-ray absorptiometry was different i.e, $9.1 \%$ and $21.2 \%$ for European and Asian Indian respectively. Lifestyle and other factors may be relevant: European man did marathon exercise whereas Indian man's main exercise was walking to hospital every day. Possibly genetic factor and intrauterine under-nutrition are also related to this difference as Indian man was low birth weight. This example remind us the limitations of BMI as a measure of adiposity across population. South Asian countries have the lowest prevalence of overweight when defined as $\mathrm{BMI} \geq 25 \mathrm{~kg} / \mathrm{m}^{2}$. WHO expert committee compiled the data and found higher levels of adiposity at lower BMI for Asian populations compared with white American and European populations and recommended cut-off points of BMI $>23$ $\mathrm{kg} / \mathrm{m}^{2}$ for overweight and $>27.5 \mathrm{~kg} / \mathrm{m}^{2}$ for obesity in Asian population [6]. However, a more accurate obesity should be more appropriately based on total amount of body fat. The upper limits of body fat for defining obesity have been set as $25 \%$ for males and
$30 \%$ for females [7]. A BMI of $30 \mathrm{~kg} / \mathrm{m}^{2}$ corresponds to $25 \%$ and $30 \%$ of body fat for males and females respectively in Caucasian [8].

A study was conducted by Dudeja., et al. [9] in 123 healthy men and women in Delhi, India to establish appropriate cut-off levels of the BMI for defining overweight and obesity. They measured body fat percent using skinfold thicknesses. The study reported that $15.1 \%$ males and $27.0 \%$ females were overweight and obese when a BMI of $>25 \mathrm{~kg} / \mathrm{m}^{2}$ was applied as the cut-off level. However, when $>25 \%$ and $>30 \%$ of fat percent were used as cut-off levels for defining overweight and obese, $34.8 \%$ and $89.2 \%$ males and females were overweight and obese respectively. To determine cutoff levels of BMI, they used body fat percent as $25 \%$ for males and $30 \%$ for females as the standard and found that the BMI of $21.5 \mathrm{~kg} /$ $\mathrm{m}^{2}$ and $19.0 \mathrm{~kg} / \mathrm{m}^{2}$ in males and females respectively. These cut-off levels of BMI were lower than WHO recommended values for Asian population.

Shaikh., et al [10] carried out a study in rural area of northwest Bangladesh and a total 1009 women were recruited at 3 months postpartum period. In this area, women do household chores, work in paddy field and $40 \%$ are underweight $\left(\mathrm{BMI}<18.5 \mathrm{~kg} / \mathrm{m}^{2}\right)$. Mean (SD) age (year) weight $(\mathrm{kg})$ and height $(\mathrm{cm})$ were 26 (5.5), 43.6 (6.2) and 149.6 (5.1) respectively. Body fat percent was measured using bioelectrical impedance analysis (BIA) and skinfold thickness methods which were developed and validated against ${ }^{2} \mathrm{H}_{2} \mathrm{O}$ dilation method (reference method) in the same population. Mean (SD) fat percent was $23.5 \%$ (4.8). The ROC curve analysis indicated that a BMI of approximately $21.0 \mathrm{~kg} / \mathrm{m}^{2}$ maximized the sensitivity and specificity of identifying the cases of $30 \%$ of body fat, by either skinfold estimates or BIA. This is substantially lower than the WHO 
Health Action cut-off point (BMI $\geq 23 \mathrm{~kg} / \mathrm{m}^{2}$ ) and the WHO recommended standard cut-off point of $25 \mathrm{~kg} / \mathrm{m}^{2}$.

Other studies reported that Asian people have higher fat percent with a lower BMI compared to White populations [11]. In White males a BMI of $25.1 \mathrm{~kg} / \mathrm{m}^{2}$ and fat percent was 19.3, whereas in Asian males a BMI of $23.4 \mathrm{~kg} / \mathrm{m}^{2}$ and fat percent was 21.4 . Similarly, for White females a BMI of $23.9 \mathrm{~kg} / \mathrm{m}^{2}$ fat percent was 30.1 , whereas, for Asian females a BMI of $22.5 \mathrm{~kg} / \mathrm{m}^{2}$ and fat percent was 31.6 which indicating that higher fat percent with lower $\mathrm{BMI}$ in Asian population. In a same BMI, fat percent is different by ethnicity is also reported by Deurenberg., et al [12]. Overall fat percent was 26.1 with a BMI of $22.2 \mathrm{~kg} / \mathrm{m}^{2}$ in Chinese, fat percent was 32.0 for a BMI of $23 \mathrm{~kg} / \mathrm{m}^{2}$ in Thai population, and fat percent was 29.3 for a BMI of $22.4 \mathrm{~kg} / \mathrm{m}^{2}$ in Indonesian.

Above mentioned evidences suggest that the relationship between percent body fat and BMI is different among different population and different ethnic groups. For public health implications the definitions of BMI cut-off levels as a diagnostic tool for obesity determination need to be population-specific instead of using WHO cut-off point of $30 \mathrm{~kg} / \mathrm{m}^{2}$ for obesity determination.

\section{Bibliography}

1. Whitlock G., et al. "Body-mass index and cause-specific mortality in 900000 adults: collaborative analyses of 57 prospective studies". Lancet 373 (2009): 1083-1096.

2. Kodama S., et al. "Comparisons of the strength of associations with future type 2 diabetes risk among anthropometric obesity indicators, including waist-to-height ratio: a meta-analysis". American Journal of Epidemiology 176 (2012): 959-969.

3. Bray GA. "Medical consequences of obesity". The Journal of Clinical Endocrinology and Metabolism 89 (2004): 2583-2589.

4. Abdullah A., et al. "The magnitude of association between overweight and obesity and the risk of diabetes: a meta-analysis of prospective cohort studies". Diabetes Research and Clinical Practice 89 (2010): 309-319.

5. Kelly T., et al. "Global burden of obesity in 2005 and projections to 2030". International Journal of Obesity (Lond) 32 (2008): 1431-1437.

6. WHO Expert Committee. "Appropriate body-mass index for Asian populations and its implications for policy and intervention strategies". Lancet 363 (2004): 157-163.
7. Hortobagyi T., et al. "Sensitivity and specificity of the Quetelet index to assess obesity in men and women". European Journal of Clinical Nutrition 48 (2004): 769-775.

8. Deurenberg P., et al. "Body mass index as a measure of body fatness: age and sex specific predictive formula". British Journal of Nutrition 65 (1991): 105-114.

9. Dudeja V., et al. "BMI does not accurately predict overweight in Asian Indians in northern India". British Journal of Nutrition 86 (2001): 105-112.

10. Shaikh S., et al. "Excessive adiposity at low BMI levels among women in rural Bangladesh". Journal of Nutrition science 5 (2016): 1-9.

11. Wang J., et al. "Asians have lower body mass index (BMI) but higher percent body fat than do whites: comparisons of anthropometric measurements". American Journal of Clinical Nutrition 60 (1994): 23-28.

12. Deurenberg P., et al. "Body mass index and percent body fat: a meta analysis among different ethnic groups". International Journal of Obesity 22 (1998): 1164-1171.

\section{Volume 3 Issue 8 August 2019 (C) All rights are reserved by Saijuddin Shaikh.}

